\title{
JUSTICIA CONSTITUCIONAL, ROL DEL JUEZ Y DIÁLOGO JURISDICCIONAL: EL CASO DE CHILE
}

\author{
Constitutional Justice, the Judge's Role and \\ Jurisdictional Dialogue: The Chilean Case
}

\author{
GONZALO AGUILAR CAVALLO' \\ Centro de Estudios Constitucionales de Chile, \\ Universidad de Talca (Chile) \\ gaguilarch@hotmail.com
}

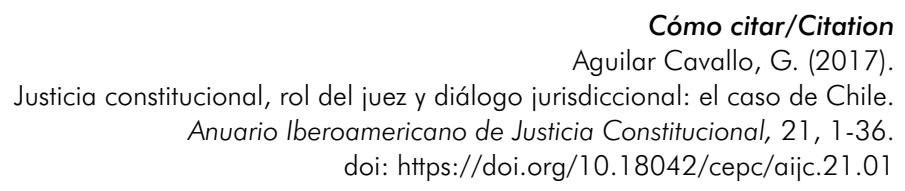

Resumen

Este estudio comienza examinando los casos Eichin y Antilef ante el Tribunal Constitucional chileno sobre competencia de la justicia militar. En estos casos, el Tribunal recurrió tanto a la Convención Americana sobre Derechos Humanos como a la jurisprudencia de la Corte Interamericana de Derechos Humanos. La presente investigación aborda la interrogante acerca de si es posible considerar los casos sobre justicia militar como ejemplos de cambio de paradigma en derecho público y de

1 Abogado (Chile), doctor en Derecho (España), magíster en Relaciones Internacionales (España), máster en Derechos Humanos y Derecho Humanitario (Francia). Postdoctorado en el Max Planck Institute for Comparative Public Law and International Law (Heidelberg, Alemania). Profesor de Derecho, director del Magíster en Derecho Constitucional y subdirector del Centro de Estudios Constitucionales de Chile, Universidad de Talca (Santiago, Chile). 
diálogo entre tribunales. Nosotros planteamos que los casos mencionados relativos a la competencia de la justicia militar en Chile constituyen un ejemplo de la transición hacia un nuevo paradigma constitucional caracterizado por una intensificación del diálogo entre jueces en materia de derechos humanos.

\section{Palabras clave}

Corte Interamericana de Derechos Humanos; jurisprudencia interamericana; jurisdicción militar; nuevo derecho público; diálogo entre jueces.

\section{Abstract}

This paper starts analyzing the Constitutional Court's Eichin and Antilef cases on the scope of the competence of the military justice in Chile. In Eichin and Antilef, the Constitutional Court applied both the Inter-American Convention on Human Rights and the Inter-American Court of Human Rights case-law. The research addresses the question of whether these cases reflect a paradigm shift in public law and of dialogue between judges. We argue that Eichin and Antilef cases are examples of a process of transition toward a new constitutional paradigm, which is essentially marked by the intensification of the dialogue between judges in human rights.

\section{Keywords}

Inter-American Court of Human Rights; Inter-American case-law; military justice; new public law; dialogue between judges. 


\section{SUMARIO}

I. INTRODUCCIÓN. II. ROL DEL JUEZ Y DIÁLOGO JURISDICCIONAL: 1. El Uso del derecho internacional y comparado en la esfera de los derechos humanos: 1. 1. Papel clave del análisis comparado. 1.2. El control de convencionalidad. 1.3. Juez nacional como juez común de derecho europeo o de derechos humanos. 2. Modalidades del diálogo entre jueces: 2.1. La utilidad y legitimidad del diálogo. 2.2. Diálogo entre jueces e interpretación. III. LA JURISPRUDENCIA CONSTITUCIONAL SOBRE JURISDICCIÓN MILITAR: 1. Los derechos reconocidos en instrumentos internacionales de derechos humanos: 1.1. Norma fundante del bloque constitucional de derechos fundamentales. 1.2. Elemento interpretativo determinante o papel significativo de los estándares internacionales. 2. La jurisprudencia de la Corte Interamericana de Derechos Humanos. IV. CONCLUSIONES. BIBLIOGRAFía.

Il ne suffit pas que la justice soit équitable, il faut qu'elle soit vécue et ressentie comme telle. Maus (2004: 26)

\section{INTRODUCCIÓN}

En el año 2014, el Tribunal Constitucional chileno pronunció dos sentencias donde declara la inaplicabilidad por inconstitucionalidad de la justicia militar en casos que involucran víctimas civiles o cuyo aspecto de fondo trata de un ilícito penal común. En ambos casos, el Tribunal apoyó su argumentación en abundantes referencias tanto al derecho internacional convencional de los derechos humanos como a la jurisprudencia de la Corte Interamericana de Derechos Humanos (Corte IDH). A partir de estos ejemplos, surgen las siguientes preguntas: ¿podrían estos casos ser considerados una muestra del rol protagónico del juez bajo el prisma de un nuevo paradigma jurídico? ¿Podrían estos casos ser demostrativos del aumento en potencia del juez constitucional en el contexto de la emergencia de un nuevo derecho público? ¿Existe en estos casos un diálogo entre jueces? Nuestra posición consistiría en argumentar 
que los fallos recientes del Tribunal Constitucional chileno, a propósito de la competencia de la justicia militar, constituyen una muestra de lo que podría denominarse un cambio de paradigma jurídico, especialmente, en el ámbito constitucional. Este cambio de paradigma tendría como telón de fondo la lenta emergencia de un nuevo derecho público y como característica el rol protagónico del juez y el diálogo multinivel interjudicial.

Este trabajo tiene por objeto analizar, en el contexto chileno, si el rol protagónico del juez, sobre todo, en el derecho público, ha estimulado un diálogo entre tribunales de distintas jurisdicciones estatales, e, incluso, con jurisdicciones internacionales. Asimismo, buscamos ilustrar la noción de diálogo y el papel del juez en un emergente nuevo derecho público a través de casos de jurisprudencia del Tribunal Constitucional chileno. Debemos dejar claro desde un comienzo que nuestro enfoque, acerca del diálogo y del rol creciente del juez, como muestra del forjamiento de un nuevo derecho público, se centra en los derechos humanos.

Por esta razón, este estudio se encuentra dividido en una primera parte, donde, a partir de ejemplos de casos jurisprudenciales, analizaremos el rol protagónico del juez y el diálogo entre jueces. En una segunda parte, abordaremos el examen de los casos de jurisprudencia, relativos a la competencia de la justicia militar, los cuales pueden revelar el papel de creciente importancia del juez, del diálogo interjurisdiccional y del control de convencionalidad.

\section{ROL DEL JUEZ Y DIÁLOGO JURISDICCIONAL}

En el mundo contemporáneo y, en parte, debido al proceso de globalización, se han desarrollado distintos conceptos de diálogo (Bogdandy, 2013: 55). En este estudio, nos interesa centrarnos en el diálogo entre jueces y, particularmente, en la esfera de los derechos humanos. ¿En qué consiste este diálogo? Podría expresarse en una plática entre dos o más jueces que manifiestan sus ideas intentando encontrar acuerdos (Aguilar, 2015: 55-102) ${ }^{2}$. En este sentido, el diálogo entre jueces se entendería como una discusión, una concertación, una búsqueda de consensos, lo cual es especialmente relevante y potente en el terreno de los derechos humanos. Bajo este prisma, el diálogo evita intercambiar en torno a las cosas que molestan o desunen y evade, por

2 El diálogo entre jueces pretendería significar una plática entre dos o más jueces u órganos jurisdiccionales, que alternativamente manifiestan sus ideas, en busca de avenencia. 
cierto, toda comunicación que implique plantear o reconocer la cuestión de la autoridad de unos sobre otros (Sudre, 2007: 7-9; Grabarcyk, 2007: 21).

El diálogo entre jueces aparece como un elemento consubstancial a lo que Bogdandy llama el nuevo derecho público (Bogdandy, 2013: 55-56). El diálogo entre jueces pone de manifiesto el nuevo paradigma del modelo constitucional multinivel (Aguilar, 2013: 55-102). En efecto, estos intercambios, comunicaciones, debates o confrontaciones entre jueces, acerca del sentido y alcance de una disposición de derechos humanos, se pueden plantear entre un juez nacional y un juez internacional o supranacional (Suxe, 2007: 158-191).

Bajo este nuevo paradigma, el juez se ve en la obligación de tener que justificar integralmente su decisión, proporcionando argumentos suficientes y convincentes. Hoy en día, el argumento de autoridad en la decisión judicial viene dado por la justificación proporcionada por el juez (Bogdandy, 2013: 55-56). El diálogo entre jueces es una manifestación notable de los procesos a los que ha llevado la globalización y la emergencia de los derechos humanos como un potencial derecho mundial, plagado de una constelación de derechos nacionales donde ningún orden interno puede reclamar jerarquía sobre otro en base a un orden de precedencia. Por eso en este contexto, a falta de jerarquía, el diálogo y la persuasión que lo acompaña, se transforman en una herramienta útil que se ejercita a través del derecho comparado.

Esta sección aborda, primero, el uso y el recurso al derecho internacional y extranjero en materia de derechos humanos y los mecanismos y técnicas desarrolladas para ello, y, posteriormente, examina las diversas modalidades del diálogo que se concretan a través de diferentes tipos de interpretación de los derechos.

\section{EL USO DEL DERECHO INTERNACIONAL Y COMPARADO EN LA ESFERA DE LOS DERECHOS HUMANOS}

En los casos de jurisprudencia constitucional chilena Eichin y Antilef, que se examinarán más adelante, el Tribunal Constitucional usa y recurre al derecho internacional de los derechos humanos, tanto en su vertiente aplicativa como en su vertiente interpretativa. En este examen el Tribunal Constitucional hace uso de los elementos comparativos que a continuación se mencionarán, donde recurre a la normativa internacional, pero, sobre todo, utiliza la jurisprudencia de la Corte IDH. Los jueces constitucionales chilenos, al momento de abordar la jurisprudencia interamericana, hacen la distinción entre casos contra el Estado de Chile y casos contra terceros Estados. En ambas situaciones, los jueces constitucionales chilenos usan información para construir su razonamiento y justificar la trayectoria de su decisión. Por ello, es necesario primeramente examinar las estrategias teóricas en materia de 
recurso al derecho extranjero o a la interpretación internacional en la esfera del ejercicio del control de convencionalidad.

Por lo tanto, en esta parte, en primer lugar, pretendemos abordar el análisis de la comparación en el ámbito de los derechos humanos en sentido amplio, esto es, incluir tanto el derecho (constitucional) extranjero y el derecho internacional de los derechos humanos. Sabido es que el derecho extranjero no es vinculante para el juez nacional, pero puede revelarse como una herramienta útil en su proceso argumentativo. Por otra parte, el derecho internacional de los derechos humanos podría llegar a ser vinculante si se cumplen con los requerimientos del derecho interno. En segundo lugar, dentro de los mecanismos de recurso al derecho internacional de los derechos humanos, en este apartado, queremos incluir una referencia al control de convencionalidad que se revela como un medio efectivo para concretar este uso, especialmente, en el ámbito del derecho internacional de los derechos humanos. Y, finalmente, en el contexto del uso del derecho internacional de los derechos humanos, en esta sección, queremos referirnos al juez nacional como el juez de derecho común.

\subsection{Papel clave del análisis comparado}

El diálogo entre jueces tiene grandes posibilidades de desencadenarse entre el nivel nacional y el nivel internacional o supranacional —esto es, multinivel-, con una dosis de intensidad en el ámbito de los derechos fundamentales. Las lecciones de lo anterior se pueden extraer tanto del sistema europeo de protección de los derechos humanos como del sistema interamericano de derechos humanos (Cartabia, 2009: 537-568; 2010). Por eso, uno de los aspectos cruciales que resaltan en este nuevo paradigma, vinculado con la importancia creciente que adquiere la argumentación jurídica en las decisiones del juez, es el papel clave que juega el derecho comparado en el forjamiento de este nuevo derecho público (Ponthoreau, 2005: 7-27; Jacquelot, 2007: 8). En este sentido, refiriéndose a la mundialización que conduce a los jueces a dialogar mas allá de las fronteras, cabe afirmar que el diálogo entre jueces se constata en "la presencia del derecho extranjero en el razonamiento del juez interno» (Allar, 2008: 93-138; Hennebel, 2008: 45-92; Stone 2014: 25). Cada vez más, los jueces nacionales no vacilan en tomar prestado un principio de interpretación de otros sistemas jurídicos.

A nuestro modo de ver, esto es un elemento positivo, que aporta dinamismo y cambio en la impartición de justicia, sobre todo en el ámbito de los derechos humanos. En esta materia, hemos hablado del rol protagónico del juez, pero lo cierto es que esto requiere de un esfuerzo conjunto (Vescoci, 1998: 1553-1567). Las partes en una controversia también debe jugar 
un papel proponiendo soluciones de derecho comparado, y por cierto, recurriendo al derecho internacional de los derechos humanos ${ }^{3}$. Incluso la intervención de terceros es relevante porque aporta, además, una dosis de deliberación y apertura democrática al proceso jurisdiccional, obligando así «a los jueces a un ejercicio comparativo». De este modo, si bien los jueces «no están obligados a tomar en consideración el derecho extranjero, no pueden ignorarlo». (Allar, 2008: 93-138; Hennebel, 2008: 45-92; Stone, 2014: 25).

Los derechos fundamentales, por su aspiración de universalidad, constituyen un terreno particularmente adecuado para desplegar un diálogo multinivel entre jueces (Habermas, 2010: 105-121). Algunos autores mencionan que los derechos humanos «ofrecen un ambiente particularmente fértil para el diálogo entre jueces» o constituyen «un campo privilegiado de los crecientes intercambios entre jurisdicciones». (Hennebel, 2007: 31; Dubout y Touze, 2009: 13). Algunos autores se refieren incluso a la idea de que se ha forjado una comunidad de intérpretes de los derechos humanos (Dulitzky, 2015: 45-93). Como se ha sostenido, el análisis comparativo se puede producir tanto respecto del derecho extranjero, particularmente, del derecho constitucional, como respecto del derecho internacional de los derechos humanos. Ya hemos señalado que en el primer caso el derecho extranjero no es vinculante mientras en el segundo caso, el derecho internacional de los derechos humanos sí es vinculante para el Estado que lo ha contraído. En este último caso, es el enfoque material el que nos induce a la comparación toda vez que debe ser el mejor derecho, el más protector, el más favorable, aquel que resulte finalmente aplicable o que prevalezca en la interpretación del juez nacional. En el caso Eichin y Antilef, el Tribunal Constitucional chileno ha realizado un análisis comparativo en este último sentido, en relación con el derecho internacional de los derechos humanos, intentando dilucidar el mejor derecho, el más favorable para las personas o grupos vulnerables. En América, esta estrategia analítica ha sido vehiculada especialmente a través de la doctrina del control de convencionalidad.

3 Acerca de la interpelación de terceros para que el juez interactúe con el derecho comparado e internacional, véase en el ámbito del derecho a la igualdad, Amicus Curiae de Libertades Públicas ante el Tribunal Constitucional de Chile, a favor de la eventual declaración de inaplicabilidad del artículo 102 del Código Civil en el procedimiento Rol 1881-2010. Disponible en: http://www.tribunalconstitucional.cl/wp/ expedientes?rol=1881-10; En el ámbito del derecho a la educación, Amicus Curiae del Instituto Nacional de Derechos Humanos ante la Corte de Apelaciones de Santiago, en los autos sobre Recurso de Protección Rol 2266-2012. Disponible en: http://www. indh.cl/wp-content/uploads/2012/03/amicus-curriae-liceo7-marzo2012.pdf. 


\subsection{El control de convencionalidad}

El control de convencionalidad consiste en el control realizado, especialmente, por un juez nacional acerca de la conformidad del derecho estatal con los tratados internacionales. Este control ha sido desarrollado doctrinaria y jurisprudencialmente en América y también en Europa, en la esfera de los sistemas de protección de los derechos humanos (Sudre, 2007: 7-9; Hertig, 2012: 29). En este último continente, la doctrina ha sido especialmente activa en vincular control de convencionalidad con un nutrido diálogo entre jueces.

Para llevar a cabo este diálogo, en el contexto de un control de convencionalidad, los jueces recurren a distintos principios de interpretación, tales como la interpretación armónica y la interpretación conforme (Saiz, 2015: 279-326). En este esquema, el principio pro homine resulta crucial porque es un eje articulador del diálogo entre jueces ${ }^{4}$.

El diálogo entre jueces, sobre todo, aquel considerado multinivel, se encuentra en íntima relación con el control de convencionalidad. Así, en el contexto de este diálogo, en el ámbito de los derechos humanos, el control de convencionalidad del derecho nacional - Constitución, ley, reglamento- se presenta como una de las técnicas a las que puede recurrir el juez estatal para armonizar el derecho interno con el derecho internacional de los derechos humanos (Hertig, 2012: 29). Desde esta perspectiva, el juez nacional se transformaría en un fiscalizador del legislador, usando como parámetro de control, no solo el texto convencional sino además la jurisprudencia del órgano autorizado para interpretarlo (Sagües, 2011: 406).

Existe una interacción notable en materia de derechos fundamentales entre la fuente interna y la fuente internacional o supranacional. La tutela de los derechos fundamentales en la Unión Europea, en el ámbito del Consejo de Europa y en la esfera estatal constitucional debe ser realizada en forma integrada e integral. De este modo, debería siempre apuntarse a «la máxima expansión de la garantía de todos los derechos» y se debería tomar en cuenta «los principios relevantes, constitucionales y supranacionales, considerados conjuntamente, que siempre se encuentran en relación de integración y recíproco balance» (Tria, 2012: 34). Esta idea de un diálogo multinivel entre jueces

4 Art. 29, Convención Americana sobre Derechos Humanos (Pacto de San José). San José, Costa Rica 7 al 22 de noviembre de 1969; art. 5, Pacto Internacional de Derechos Civiles y Políticos. Adoptado por la Asamblea General el 16 de diciembre de 1966; art. 53, Convenio para la Protección de los Derechos Humanos y de las Libertades Fundamentales. Roma, 4.XI.1950; art. 53, Carta de los derechos Fundamentales de la Unión Europea (2010/C 83/02) ES 30.3.2010 Diario Oficial de la Unión Europea C 83/389. 
apuntando a la máxima expansión de los derechos y libertades ya ha sido reiterada, por ejemplo, por la jurisprudencia constitucional italiana ${ }^{5}$.

En esta coyuntura, se puede observar claramente que, en lo que toca a la interpretación jurídica de los derechos humanos, «la cuestión del quid iuris, o sea, la conformidad del juicio al mandato de la ley, permanece todavía estrechamente conectado a aquella del quid ius, o sea, del valor intrínseco que se encuentra a la base de la norma jurídica» (Frosini, 1991: 9-19). Justamente, es ese valor intrínseco el que otorga la posibilidad de realizar el efecto expansivo de los derechos humanos. De ahí, la relevancia, en este nuevo paradigma, de la interpretación como práctica y de los derechos fundamentales como expresión de valores compartidos.

\subsection{Juez nacional como juez común de derecho europeo o de derechos humanos}

El control de convencionalidad convierte al juez nacional en el juez de derecho común. En el ámbito de la Unión Europea será el juez de derecho común del derecho europeo. (Le Pourhiet, 2010: 363-365). En la esfera de la Convención Europea de Derechos Humanos será el juez de derecho común de la convencionalidad de derechos humanos.

Incluso algunos afirman que el juez nacional, comprendiendo al juez constitucional, será el intérprete de derecho común de la Convención Europea de Derechos Humanos. (Andriantsimbazovina, 2005: 148-153; Lavade, 2005: 133-127). Según Maus, precisamente, este último sería el entendimiento que se le daría al control de convencionalidad por los jueces nacionales en el contexto de sistema europeo de derechos humanos. En efecto, «[e]1 sistema de la Convención Europea puede ser aplicado también por las jurisdicciones nacionales a título de control de convencionalidad, cuando estas deben descartar disposiciones del derecho nacional por no respetar las normas de la Convención Europea tal como son interpretadas por la Corte» (Maus, 2004: 25$)^{6}$.

5 Corte costituzionale italiana: Sentenze 191 del 2014; 170 e 85 del 2013, 264 del 2012.

6 Según Maus «ninguna jurisdicción nacional ha considerado que en su orden interno, disposiciones de valor constitucional debían ser descartadas a raíz del control de convencionalidad. Sin embargo, tal hipótesis no es inconcebible, en particular cuando permanecen en las constituciones nacionales normas que han sido adoptadas en un período no democrático» (Maus, 2004: 14-26). 
En este rol, el juez nacional, aplicador e intérprete de derecho común de normas internacionales y supranacionales, adquirirá las potestades para descartar o no aplicar normas nacionales, incluso, disposiciones de valor constitucional, sobre todo, cuando ellas entran en colisión o arrojan problemas de interpretación con normas internacionales y supranacionales, las que, considerando su interpretación autorizada, otorgan un estándar de protección del individuo más elevado ${ }^{7}$. Cabe aquí tener presente, sobre todo como lección para Chile, que ya hace más de quince años, la jurisprudencia del Tribunal Federal suizo ha confirmado la primacía del derecho internacional, sobre todo, cuando se trata de derechos humanos ${ }^{8}$.

Así, el control de convencionalidad y el diálogo entre jueces no significa sumisión ni subordinación de ninguna especie? . De hecho, un tribunal nacional puede perfectamente desmarcarse de la postura de otro tribunal de derechos humanos, a través de la denominada interpretación constructiva, yendo más allá que la propia interpretación del órgano jurisdiccional internacional, cuando el principio pro homine lo exige, principio que constituye el nervio neurálgico del sistema de derechos humanos (Sudre, 2003: 200). En esta línea, la Corte Europea de Derechos Humanos (Corte EDH), en el

7 Refiriéndose al control de convencionalidad Hertig afirma la facultad de los jueces suizos de rechazar la aplicación de una ley federal contraria a la Convención [Europea de Derechos Humanos], apoyándose sobre todo en la primacía del derecho internacional y en la importancia particular de los tratados en materia de derechos humanos (Hertig, 2012: 19-59).

8 «Diese völkerrechtlichen Prinzipien sind in der schweizerischen Rechtsordnung unmittelbar anwendbar (BGE 117 Ib 337 E. 2a S. 340) und binden nicht nur den Gesetzgeber, sondern sämtliche Staatsorgane (vgl. die gemeinsame Stellungnahme des Bundesamtes für Justiz und der Direktion für Völkerrecht vom 26. April 1989, VPB 53/1989 Nr. 54 Ziff. 15 S. 420 ff.). Daraus ergibt sich, dass im Konfliktfall das Völkerrecht dem Landesrecht prinzipiell vorgeht (BGE 122 II 485 E. 3a S. 487; BGE 122 II 234 E. 4e S. 239; BGE 109 Ib 165 E. 7b S. 173; BGE 100 Ia 407 E. 1b S. 410; BGE 125 III 209 E. 6e in fine). Dies hat zur Folge, dass eine völkerrechtswidrige Norm des Landesrechts im Einzelfall nicht angewendet werden kann. Diese Konfliktregelung drängt sich umso mehr auf, wenn sich der Vorrang aus einer völkerrechtlichen Norm ableitet, die dem Schutz der Menschenrechte dient». ATF 125/1999 II 417. Urteil der I. öffentlichrechtlichen Abteilung vom 26. Juli 1999 i.S. A. gegen Schweizerische Bundesanwaltschaft, Eidgenössisches Justiz- und Polizeidepartement und Schweizerischen Bundesrat (Verwaltungsgerichtsbeschwerde). Consid. 4 d).

9 «[L]as autoridades nacionales permanecen libres de elegir las medidas que ellas estimen apropiadas para la implementación de sus obligaciones convencionales» (Sudre, 2003: 200). 
famoso caso Sunday Times, afirmó que aun cuando la Convención Europea de Derechos Humanos establece ciertos estándares internacionales que deben ser observados por los Estados contratantes, «eso no quiere decir que una uniformidad absoluta es requerida, $y$, en efecto, si bien los Estados contratantes son libres para elegir las medidas que ellos consideran apropiadas, la Corte no puede ser indiferente ante los rasgos sustanciales o procesales de sus respectivas normas internas» ${ }^{10}$.

En último término, el criterio rector que guía e ilumina la actuación del juez nacional ha sido despejado por la doctrina y por la jurisprudencia. En efecto, lo que se requiere al momento de proporcionar una tutela judicial efectiva a un derecho es de determinar cuál de las diversas fuentes disponibles ofrece un nivel de protección más adecuado, teniendo en consideración la jurisprudencia pertinente ${ }^{11}$.

Esta es la experiencia que nos ha aportado el Tribunal Constitucional alemán con los casos Solange I (1974) y Solange II (1998), en el sentido de la supremacía del derecho comunitario o europeo, mientras que mantenga, al menos, el mismo nivel de protección que proporciona el sistema constitucional de derechos fundamentales ${ }^{12}$.

El uso del derecho internacional de los derechos humanos por parte del juez nacional a través del mecanismo del control de convencionalidad convirtiéndolo en el juez común de los derechos humanos permite visualizar una realidad práctica, cual es la existencia de un diálogo. Los distintos intercambios entre el juez nacional y el juez internacional se producen en varios sentidos y el resultado de ello puede ser incierto, como se verá a continuación, dependiendo del tipo de diálogo que se entable.

10 "This does not mean that absolute uniformity is required and, indeed, since the Contracting States remain free to choose the measures which they consider appropriate, the Court cannot be oblivious of the substantive or procedural features of their respective domestic laws". ECtHR: Case of the Sunday Times v. The United Kingdom. (Application $\mathrm{N}^{\circ}$ 6538/74). Judgment, 26 April 1979, para. 61. (T. del A.).

11 Tria indica que si el juez nacional necesita recurrir a fuentes supranacionales y/o internacionales, para asignar una tutela mejor, «debe determinar cuál de las mencionadas fuentes ofrece un nivel de protección más adecuado, teniendo también en consideración la jurisprudencia pertinente de la Corte de Luxemburgo y de Estrasburgo» (Tria, 2012: 34).

12 Tribunal Constitucional alemán. 29 de mayo de 1974, BVerfGE 37, 27, que resolvió el caso Internationale Handelsgesellschaft, más conocido como, Solange I, Disponible en: https://www.bundesverfassungsgericht.de; Tribunal Constitucional alemán. 22 de octubre de 1986, BVerfGE 73, 339, 2 BvR 197/83, caso Solange II. Disponible en: https:// www.bundesverfassungsgericht.de. 
Como se observará más adelante en la segunda parte, el juez constitucional chileno, ha realizado esta misma indagación en casos de justicia militar, intentando determinar cuál es el estándar de protección más alto, si el nacional o el internacional. En este proceso indagatorio, el juez nacional chileno ha recurrido a algunas de las distintas fórmulas de diálogo entre jueces.

\section{MODALIDADES DEL DIÁLOGO ENTRE JUECES}

Las distintas modalidades de diálogo se presentan al amparo de la interpretación en derechos humanos. Por eso los distintos tipos de diálogo se traducen en distintas variedades de interpretación. Nuestra postura inicial es que el juez constitucional chileno en los casos Eichin y Antilef ha realizado un tipo específico de diálogo y, por tanto, ha recurrido a una variedad determinada de interpretación, de las que se analizarán a continuación. En otras palabras, Eichin y Antilef serían dos ejemplos de la realidad de este diálogo entre jueces en el orden constitucional chileno. Intentaremos en este trabajo darle un trasfondo teórico a la experiencia derivada de la práctica constitucional chilena en los casos mencionados.

Para efectuar el análisis de las distintas modalidades que puede adquirir el diálogo entre jueces, quizás conviene tener en consideración, primero, que «el diálogo entre jurisdicciones no puede concebirse sin una cierta autonomía del juez nacional» (Grabarczyk, 2007: 10-41). Por otro lado, cabe tener presente que la controversia es necesaria para que exista un diálogo productivo y enriquecedor, porque el seguimiento, puro y simple, en realidad, se parece más a un monólogo que a un diálogo (Grabarczyk, 2007: 25).

Para examinar las distintas modalidades de diálogo entre jueces, en primer lugar, pretendemos referirnos brevemente a la legitimidad del diálogo y, posteriormente, queremos abordar las distintas posibilidades de interpretación que puede haber cuando un juez nacional decide iniciar un diálogo con un juez internacional o supranacional.

\subsection{La utilidad y legitimidad del diálogo}

En primer lugar, es necesario mencionar que el diálogo entre jueces se hace operativo a través del derecho comparado. Recordemos que Häberle considera al derecho comparado como un quinto método de interpretación (Häberle, 2010: 387). Este método pone en evidencia la instantaneidad y la inmediatez de un mundo global, proyectado hacia el derecho, y por otra parte, releva el desarrollo, en el juez del siglo xxI, de las habilidades técnicas requeridas para poner en práctica este método. La mayor parte del tiempo, el derecho comparado estaría destinado a orientar y/o a apoyar la interpretación 
del juez, mediante el uso de citas o referencias a decisiones o argumentos pretorianos provenientes de jueces extranjeros o internacionales. Este diálogo, que pone de relieve el valor de la técnica comparatista, tiene la mayor importancia en materia de derechos humanos.

En términos generales, se puede observar prima facie que el juez nacional entrará en un diálogo con jueces extranjeros o internacionales para los siguientes efectos: a) para fundamentar su argumentación a fin de demostrar que existe en materia de derechos humanos una práctica internacional común incluso un consenso internacional; b) para legitimar una interpretación extensiva. En efecto, el juez pretende apoyar una interpretación extensiva o dinámica del derecho, y para eso alude a disposiciones más generosas de otros textos internacionales o a una jurisprudencia más protectora; c) para reforzar su razonamiento interpretativo. En este sentido, la corte se refiere a otros sistemas y textos de derechos fundamentales, e incluso a instrumentos internacionales de derechos humanos, y d) por último, es importante tener en mente que el diálogo es la vía idónea para alcanzar acuerdos o construir consensos (Duliztky, 2015: 45-93).

Sin embargo, el diálogo es comunicación e intercambio de ideas y propuestas, no es imposición. Por eso el diálogo se desarrolla sobre todo en el terreno de la interpretación y de la argumentación jurídica y, en lo que nos interesa, con asiduidad, en el ámbito de los derechos humanos. El diálogo iniciado por un juez nacional no siempre busca alinearse con la posición de jueces extranjeros o internacionales, sino, a veces, busca afirmar la razonabilidad de una posición distinta. Como quiera que este diálogo se produzca, en nuestra visión, el diálogo entre jueces nunca puede servir para mermar o disminuir los derechos y libertades de los individuos y comunidades, con respecto de la protección que otorga ya sea el orden constitucional o internacional ${ }^{13}$.

\subsection{Diálogo entre jueces e interpretación}

Tal como hemos mencionado precedentemente, el diálogo entre jueces puede adquirir la forma de una controversia, una discusión, una confrontación, un debate o un intercambio de argumentos acerca del sentido y alcance de una norma de derechos humanos, entre un juez nacional y un juez internacional (Grabarczyk, 2007: 21).

El intercambio o debate de razonamientos o argumentaciones exige naturalmente del juez interno un ejercicio de interpretación. Este ejercicio,

13 Veáse art. 5.2 del Pacto Internacional de Derechos Civiles y Políticos de 1966; art. 29 literal b) de la Convención Americana sobre Derechos Humanos de 1969. 
como hemos advertido, se vehicula, tanto en Europa como en América, preferentemente a través del control de convencionalidad. Así, los modos de interpretación retenidos por el juez interno en el ejercicio del control de convencionalidad aparecen como fundamentales para el desarrollo del diálogo de jueces. El diálogo entre jueces y las distintas formas de interpretación que este acarrea ha sido principalmente abordado por la doctrina europea con base en la experiencia cotidiana, sobre todo, derivada de la interacción con el sistema europeo de derechos humanos. El diálogo de jueces cubre varios modos de interpretación en derechos humanos, tales como la interpretación neutralizante y la interpretación conforme (Sudre, 2007: 7-9; Grabarczyk, 2007: 21; De Gouttes, 1999: 21). Asimismo, el diálogo se puede materializar a través de la interpretación, contradicción o anticipación (Grabarczyk, 2007: 41). Además, Regis de Gouttes, refiriéndose al rol que juega la norma convencional para el juez nacional, alude a una función reveladora y adyuvante de la ley nacional (De Gouttes, 199: 15).

Con todo, en nuestra visión, y dejando a salvo el caso del principio de interpretación conforme, estas manifestaciones de diálogo no corresponden a principios de interpretación en sí mismo considerados, sino más bien al resultado producto de la actividad interpretativa, tales como, contradicción, neutralización o anticipación. A partir de las propuestas precedentes de Sudre, Grabarczyk y De Goutte, a continuación, examinaremos brevemente lo que sugerimos denominar como el diálogo conforme, constructivo, anticipatorio, neutralizante, oposición. (Nogueira, 2014: in passim; Dulitzky, 2015: 45-93).

a) Diálogo bajo el modo de interpretación conforme: diálogo conforme

En el diálogo a través de la interpretación conforme al derecho nacional coincide con las interpretaciones dadas por el juez internacional de derechos humanos (Sagües, 2011: 405). El diálogo de conformidad o conforme se refiere a la técnica a la que recurre el juez nacional para armonizar el derecho nacional con el instrumento internacional convencional y corresponde específicamente a la interpretación conforme a la Convención (Ferrer, 2011: 531-622). Como señala Hertig «la interpretación conforme a la Convención deriva de la interpretación conforme al derecho internacional» (Hertig, 2012: 29). Un ejemplo claro de interpretación conforme a la Convención, emanado del derecho suizo, se refiere a un caso en el que los jueces federales aplicaron el art. 98 al. 4 (matrimonios de extranjeros en situación irregular) del Código Civil suizo en forma conforme al derecho al matrimonio consagrado en el 
art. 12 de la Convención Europea de Derechos Humanos ${ }^{14}$. Esta regla de interpretación conforme estimula un diálogo que apunta a evitar la mayor parte de los conflictos entre ambos órdenes, doméstico e internacional ${ }^{15}$.

La interpretación conforme a la Convención, y, más generalmente, al derecho internacional, apunta a lograr la convergencia de la interpretación del juez nacional con aquella del juez internacional, ajustándola a sus límites y contenidos. Los jueces constitucionales chilenos han procedido en diversas ocasiones a entablar este tipo de diálogos, realizando esta interpretación conforme. Por ejemplo, en materia de derechos del niño (respecto de los cuales la Constitución chilena guarda absoluto silencio), el Tribunal Constitucional de Chile ha declarado la inaplicabilidad por inconstitucionalidad de normas de la ley 19.968 que creó los Tribunales de Familia, considerando para estimar la inconstitucionalidad no solo la conformidad a normas internacionales sino también a la interpretación proveniente de la Corte $\mathrm{IDH}^{16}$.

14 «Au vu de ces exigences, il faut admettre que le système mis en place par le législateur suisse peut s'avérer contraire à l'art. $12 \mathrm{CEDH}$ lorsqu'un étranger, bien qu'en situation irrégulière en Suisse, désire néanmoins réellement et sincèrement se marier. En effet, en cas de refus de l'autorité de police des étrangers de régulariser - même temporairement - sa situation, il ne pourra pas, en vertu de l'art. 98 al. $4 \mathrm{CC}$, entré en vigueur le $1^{\text {er }}$ janvier 2011 (RO 20103057 ), concrétiser son projet en Suisse; ce risque est spécialement marqué pour les requérants d'asile déboutés qui ne peuvent, comme on l'a vu (supra consid. 3.1), obtenir l'ouverture d'une procédure d'autorisation de séjour qu'à des conditions relativement restrictives au regard de l'art. 14 al. 1 LAsi». ATF 137 I 351, Arrêt de la IIe Cour de droit public dans la cause X. et Y. contre Service de la population du canton de Vaud (recours en matière de droit public) 2C_349/2011 du 23 novembre 2011. Consid. 3.5.

15 «Zu diesen Fragen muss nicht abschliessend Stellung genommen werden. Es genügt festzuhalten, dass der Bundesgesetzgeber gültig abgeschlossene Staatsverträge gelten lassen will, sofern er nicht ausdrücklich in Kauf nimmt, dass völkerrechtswidriges Landesrecht zustande komme. Im Zweifel muss innerstaatliches Recht völkerrechtskonform ausgelegt werden; d.h. so, dass ein Widerspruch mit dem Völkerrecht nicht besteht. Diese Auslegungsregel erlaubt es, Konflikte zwischen den beiden Rechtsordnungen meistens zu vermeiden; sie entspricht den neuen Strömungen in Frankreich, in der Bundesrepublik Deutschland und in den Niederlanden" ATF 94/1968 I 669. Urteil vom 22. November 1968 i.S. Frigerio gegen das Eidg. Verkehrs- und Energiewirtschaftsdepartement. Consid. 6 a).

16 «Que, además, la Convención sobre los Derechos del Niño indica en su artículo primero: "niño (es) todo ser humano menor de dieciocho años de edad, salvo que, en virtud de la ley que le sea aplicable, haya alcanzado antes la mayoría de edad (Caso de los 'Niños de la Calle' (Villagrán Morales y otros) vs. Guatemala, párr. 188). 
Así, en estos casos, producto de este diálogo, el juez nacional descarta la norma nacional, alejándose de la jurisprudencia constitucional, justamente, porque practicando el control difuso de convencionalidad, el juez interno controvierte abiertamente el enfoque planteado por el órgano jurisdiccional constitucional. A este tipo de juez, Motolese les llama los «jueces verdaderos rebeldes» puesto que conocen la jurisprudencia constitucional y son conscientes de que la están controvirtiendo, en aplicación de un diálogo conforme con la norma convencional (Motolese, 2013). Por su parte, Regis de Gouttes, se refiere a este tipo de situación, como una verdadera neutralización de la ley nacional, ya que el juez nacional, aplicando la norma convencional, neutraliza el texto de la ley interna no compatible con las exigencias de la Convención (Gouttes, 1999: 14). En el caso de la Corte Suprema chilena es posible encontrar ejemplos relevantes de este tipo de interpretación. Por ejemplo, en el denominado caso de los Consejos de Guerra de 2016, la Corte, ejecutando una decisión de la Corte Interamericana de Derechos Humanos, endereza una injusticia, anula Consejos de Guerra realizados durante la época de la dictadura,

En las Reglas de Beijing, en las Reglas de Tokio y en las Directrices de Riad se utilizan los términos 'niño' y 'menor' para designar a los sujetos destinatarios de sus disposiciones. De acuerdo con las Reglas de Beijing, 'menor es todo niño o joven que, con arreglo al sistema jurídico respectivo, puede ser castigado por cometer un delito en forma diferente a un adulto'. En las Reglas de Tokio no se establece salvedad alguna al límite de dieciocho años de edad.

En definitiva, tomando en cuenta la normativa internacional y el criterio sustentado por la Corte Interamericana de Derechos Humanos, se entiende por 'niño' a toda persona que no ha cumplido dieciocho años de edad (Opinión Consultiva OC-17/02. Condición Jurídica y Derechos Humanos del Niño. Resolución de 28 de agosto de 2002, solicitada por la Comisión Interamericana de Derechos Humanos).

De esta manera, la voz 'imputado' contraría la naturaleza y esencia de la Ley de Responsabilidad Penal Juvenil, la cual vino en nuestro país a dar cumplimiento a lo ordenado en la Convención de los Derechos del Niño, cuyo fin era promover el establecimiento de procedimientos, autoridades e instituciones específicas para el juzgamiento de los niños a los que se les impute una infracción de ley penal, por lo que corresponde que los menores que estén exentos sean puestos a disposición del tribunal competente en asuntos de familia..." (Corte Suprema, roles 5440-2007, 5441-2007 y 5972-2009), (STC Rol 2743 c. 13);» Tribunal Constitucional de Chile (2007). Requerimiento de inaplicabilidad por inconstitucionalidad presentado por Nel Greeven Bobadilla, juez titular del Juzgado de Familia de Pudahuel, respecto de los arts. $102 \mathrm{~A}$ a 102 M, de la Ley 19.968, en los autos RIT I-21-2016, RUC 16-2-0173337-9, de que conoce el Juzgado de Familia de Pudahuel. Rol 3119-2016, consid. 12. ${ }^{\circ}$. 
y aplica no solo las normas internacionales de derechos humanos sino también la interpretación que de ellas ha realizado la Corte $\mathrm{IDH}^{17}$.

Por otro lado, tal como se indicará en la segunda parte de este trabajo, cuando el Tribunal Constitucional chileno, en Aichin y Antilef - consecuentemente en Jorquera - expresa que los derechos contenidos en los instrumentos internacionales de derechos humanos constituyen una fuente material para el juez interno por la vía del bloque constitucional de derechos fundamentales y su contenido sirve de elemento interpretativo determinante en el análisis constitucional jurisprudencial, y que los estándares internacionales juegan un papel significativo, a nuestro modo de ver, dicho tribunal se ubica en el diálogo conforme. Y, sobre todo, el juez constitucional chileno emprende este tipo de diálogo cuando, refiriéndose a la jurisprudencia interamericana en casos donde Chile ha sido parte, resalta que el estándar interpretativo es un elemento significativo, mientras que en casos donde Chile no ha sido parte, el juez constitucional destaca que el estándar interpretativo es un elemento complementario de análisis. En ambas situaciones, es posible observar una diferencia de intensidad, pero lo relevante es que con estos criterios, los jueces constitucionales chilenos se muestran dispuestos a iniciar un diálogo entre jueces.

b) Diálogo bajo el modo de interpretación constructiva:

diálogo constructivo

Este diálogo se basa en el principio de interpretación extensiva de los derechos fundamentales y el principio de interpretación restrictiva de las limitaciones a los derechos fundamentales, extendiendo protectoramente el campo de aplicación de los derechos reconocidos (Aguilar y Nogueira, 2016: 13-43). Entonces, el diálogo constructivo de jueces se produce gracias a interpretaciones internacionales más favorables que son incorporadas por el juez nacional en su control de derecho interno.

En consecuencia, gracias al recurso a métodos extensivos y más favorables a la interpretación de los derechos humanos por parte del juez internacional o supranacional se produce la ampliación del campo de aplicación de los derechos reconocidos por el derecho internacional de los derechos humanos (Riochet, 2007: 117). De este modo, el juez nacional, al incorporar el derecho internacional de los derechos humanos en conjunto con las interpretaciones

17 Corte Suprema de Chile (2016). Caso denominado de los Consejos de Guerra. Rol 27.543-16. 
pretorianas internacionales «se amplía ineluctablemente el ámbito de su propio control sobre el derecho interno» (ibid).

El diálogo constructivo se produce a partir del uso de métodos de interpretación creados o identificados pretorianamente por los tribunales internacionales de derechos humanos, y aplicados por los jueces nacionales, que se convierten a la sazón, en el juez común de los derechos humanos. Estos métodos extensivos de interpretación se han hecho presentes también en el ámbito del derecho internacional clásico, donde se ha insistido en la necesidad de considerar las nuevas condiciones de la vida internacional, estimulando al juez a determinar el estado actual del derecho, y si es necesario, haciéndolo en forma constructiva ${ }^{18}$.

Entre estos métodos, se pueden mencionar, por ejemplo, la interpretación evolutiva y la interpretación dinámica ${ }^{19}$. La interpretación evolutiva, desarrollada por la Corte EDH y asumida por la Corte IDH, se apoya fundamentalmente en la noción de que la Convención es un instrumento viviente ${ }^{20}$. De acuerdo con la doctrina del instrumento viviente el texto «se interpreta a la luz de las condiciones actuales y evoluciona a través de la interpretación de la Corte» (Wildhaber, 2004: 16). La doctrina del instrumento viviente $y$, en consecuencia, de la interpretación evolutiva, se aplica tanto al ámbito constitucional como internacional. En ese sentido, desde el terreno constitucional se han acuñado diferentes términos tales como constitución viviente,

18 La Corte debe «determinar el estado actual del derecho e incluso, si cabe, en forma constructiva [...] Proceder de otra manera sería desconocer la naturaleza del derecho de gentes, que debe siempre reflejar la vida internacional de donde nace, bajo pena de ser desacreditada. La forma de proceder que acaba de ser indicada es aplicada en el derecho público interno». Reservations to the Convention on Genocide, Advisory Opinion: I.C.J. Reports 1951, p. 15. Dissenting Opinion of Judge Alvarez p. 50.

19 Cour E.D.H.: Arrêt Tyrer, série A no 26, p. 15, par. 31; Cour E.D.H.: Affaire Marckx c. Belgique. (Requête $\mathrm{N}^{\circ}$ 6833/74). Arrêt, para. 41; Respecto de la interpretación dinámica: "Celle qui partant du texte de la Convention en tire une conception élargie des droits proclamés voire de l'existence de droits qui n'ont pas été primitivement perçus comme en faisant partie», (Rolland, 1990: 70-74); Sudre indica, refiriéndose a la Corte Europea de Derechos Humanos y a los métodos de interpretación finalista y teleológica, que «la interpretación finalista es también una interpretación evolutiva». Sudre, Frédéric: «Linterprétation dynamique de la Cour Européenne des Droits de l'homme». Disponible en: http://www.senat.fr/colloques/office_du_juge/office_du_ juge11.html\#fn302 2006 [Visitado el 3/1/2015] (Wildhaber, 2004: 15-27).

20 Cour E.D.H.: Affaire Ferrazzini c. Italie. (Requête $\mathrm{n}^{\circ}$ 44759/98). Arrêt, para. 26; Sobre la interpretación evolutiva del derecho a la vida por la Corte Interamericana de Derechos Humanos, véase (Cassetti, 2010: 1-17). 
constitución material, constitución invisible, constitución paralela, los cuales, quieren, en realidad, expresar una necesidad en la esfera de los derechos humanos, esto es, la exigencia de que se requiere respecto de estos textos, una reflexión abierta y deliberativa (Martens, 2007: 10). Cabe tener en mente que, sobre todo en el mundo actual, las constituciones están abiertas a influencias externas. Con todo, una crítica a la idea de constitución viviente y una defensa del significado del texto que sus autores le dieron al momento de adoptarla ha sido expresada, por ejemplo, por Scalia (Talbot, 2005: 42).

Por otra parte, a través de la interpretación dinámica, el juez internacional o supranacional no vacila en modificar sus posiciones anteriores acerca del sentido de un derecho (Tulkens et Van Drooghenbroeck, 2005: 311-325). En este sentido, realmente, los derechos humanos se hacen «vivos y vitales» a través de su interpretación (Giorgianni, 2014). El dinamismo interpretativo se ve reflejado en la ampliación de los casos de aplicación del derecho y en la extensión del contenido del derecho (Sudre, 2001: 437). El dinamismo interpretativo se ha hecho presente en el sistema europeo, en el sistema interamericano y en el ámbito constitucional chileno, llevando la acción protectora del juez, a veces, más allá de los límites objetivos del texto (Cassetti, 2010: 12). Desde la perspectiva de los jueces constitucionales, por ejemplo, el Tribunal Constitucional chileno no ha vacilado en ampliar el abanico de los derechos protegidos recurriendo a la Convención Americana sobre Derechos Humanos. Así, los jueces constitucionales han sostenido que

el derecho a la identidad personal está estrechamente ligado a la dignidad humana, en cuanto valor que, a partir de su consagración en el artículo $1^{\circ}$, inciso primero, de la Ley Suprema, constituye la piedra angular de todos los derechos fundamentales que la Ley Suprema consagra. Asimismo, que aun cuando la Constitución chilena no reconozca, en su texto, el derecho a la identidad, ello no puede constituir un obstáculo para que el juez constitucional le brinde adecuada protección, precisamente por su estrecha vinculación con la dignidad humana y porque se encuentra protegido expresamente en diversos tratados internacionales ratificados por Chile y vigentes en nuestro país (STC chileno, Rol 1340-09, 2009, consid. 9).

Los jueces internacionales y supranacionales recurren a la interpretación evolutiva y dinámica con el fin de proporcionar respuestas adecuadas, actuales y oportunas a las demandas de la sociedad contemporánea. En esta labor, al parecer, intentan encontrar puntos de acuerdo, visiones compartidas o consensos entre los Estados partes (Levinet, 2011: 232; Cour EDH: affaire Guzzardi, 1980: par. 95; Pelloux, 1981: 286-303). Ello parece más una quimera que una realidad ya que el juez, en efecto, basa su actividad más bien en el desarrollo lógico de un concepto, de un derecho o de un principio fundamental 
(Sudre, 2001: 437). ¿Por qué el juez, en este dinamismo interpretativo, sigue más el desarrollo lógico de un concepto que la búsqueda de consensos entre los Estados? Podría ser porque el juez tiene el deber de darle efectividad a los derechos reconocidos, hacer que la norma produzca todos sus efectos, llevando adelante, para ello, si es necesario, un diálogo constructivo (VV. AA., 2007: 379). La vía del diálogo constructivo aumenta en sus posibilidades de ocurrencia en la medida que la Corte se consolida como una fuente autorizada de derechos y estándares ${ }^{21}$.

c) Diálogo bajo el modo de interpretación anticipatoria: diálogo anticipatorio

La anticipación implica una forma de diálogo entre un juez nacional y el juez internacional donde el juez nacional debe pronunciarse antes del control de convencionalidad efectuado por el juez internacional, ya sea sobre temas donde el tribunal internacional se ha pronunciado con anterioridad o no.

El diálogo anticipatorio es una manifestación del principio de subsidiariedad que opera en el ámbito de los derechos humanos (Hertir, 2012: 25). Este principio de subsidiariedad articula la interacción entre la protección nacional y la protección internacional de los derechos humanos. En el ámbito americano cabe precisar la particularidad de que «la protección internacional es de naturaleza coadyuvante o complementaria de la que ofrece el derecho interno de los Estados». Por esta razón, el juez nacional, sabiendo esto, tiene la posibilidad de anticiparse a la interpretación dada por el juez internacional, proponiéndole en este sentido, al juez internacional una pauta interpretativa nueva, o bien, más protectora. En este caso, podríamos decir, utilizando las palabras de Tizzano, que lo importante aquí no es quién tiene la última palabra, sino, más bien quién tiene la primera palabra (2011: 29-57). Con esto, se realizaría el principio de que los sistemas de protección de los derechos humanos serían complementarios y, por el contrario de colisionar, se enriquecerían mutuamente.

La parte más enriquecedora de este diálogo se podría encontrar en los casos en que el juez nacional debe pronunciarse sobre situaciones de violación de derechos humanos donde el tribunal internacional no se ha pronunciado con anterioridad. En estos casos, el juez nacional puede liderar el desarrollo del

21 "[A]s the European Court has consolidated its role as a primary, authoritative source of rights doctrine and standards, the interest national judges have in constructively engaging the Court in dialogue increases» (Stone, 2014: 22-26). 


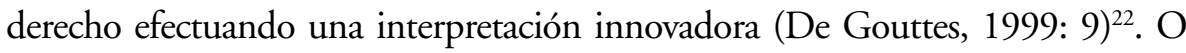
bien, si se trata de casos donde el juez internacional ya se ha pronunciado, el juez nacional podría efectuar una interpretación extensiva, ampliando el contenido protector de los derechos (Madelaine, 2007: 132). Estos casos, tienen la particularidad de que el juez nacional antecede al juez internacional en la interpretación de los derechos, pudiendo liderar la interpretación de los derechos reconocidos en la Convención, si es que logra que los jueces internacionales de derechos humanos dialoguen positivamente con su argumentación. (Milano, 2006: 448).

El diálogo anticipatorio del juez nacional respecto del juez internacional es doblemente útil desde la perspectiva del justiciable. Por una parte, evita que el justiciable recurra al amparo internacional de derechos y, por otra, mejora la efectividad de los derechos, generando, al mismo tiempo, un enriquecimiento mutuo entre ambas jurisdicciones. (Madelaine, 2007: 133; Milano, 2006: 448).

d) Diálogo bajo el modo de interpretación neutralizante: diálogo neutralizante

La interpretación neutralizante implica una limitación directa por parte del juez interno de convencionalidad de las obligaciones que emanan de la Convención. Por medio de esta interpretación se neutralizan las nociones que derivan del derecho internacional convencional desarrolladas por la jurisprudencia autorizada y se neutraliza el control de proporcionalidad que el juez internacional de los derechos humanos pueda efectuar. Con esto, se estaría redefiniendo, a la baja, la extensión del poder de control del juez internacional. Las principales armas de esta estrategia neutralizante del juez nacional serían dos. Por una parte, la reivindicación del denominado margen de apreciación nacional (García, 2010: in passim). Por otra parte, en ciertas ocasiones, manifestando una idea inversa de la subsidiariedad, también se pretende izar, para estos efectos, la bandera de la identidad constitucional nacional (Le Pourhiet, 2010: 363-365; Dubois, 2007: 72-96).

El diálogo a través de la interpretación neutralizante es definido por Sudre como «una estrategia de desvío o evitación apuntando a neutralizar la interpretación europea creando así, por medio de una interpretación un poco forzada del derecho nacional, incluso mediante una especie de re-escritura-

22 Regis de Gouttes señala que el juez nacional puede encontrar en la Convención Europea de Derechos Humanos, así como en los principios de interpretación por ella desarrollados una fuente de ampliación de su poder creador del derecho (De Gouttes, 1999: 7-20). 
ción de la ley, una relación de adecuación entre el derecho interno y la norma europea» (2004: 210; Sagües, 2011: 405). En el diálogo conforme existe concordancia en las interpretaciones, mientras que en el diálogo neutralizante hay sumisión en apariencia pero contradicción en el fondo, y, por consecuencia, no permite una aplicación sistemática y plena de las disposiciones de la Convención y no garantiza el respeto efectivo de sus normas (Dubois, 2007: 72-96).

En definitiva, la interpretación neutralizante anestesia los efectos principales de las normas y de la interpretación autorizada de los derechos humanos. La neutralización se produce porque con la interpretación del juez nacional es posible apartarse de la interpretación internacional, bajo la apariencia de que se entra en diálogo con el juez internacional, y sin aparecer vulnerando ni la norma ni la interpretación internacional (Dubois, 2007: 72-96). Se trata de una interpretación efectuada por el juez nacional sin tener la intención de cumplir con el estándar mínimo proveniente del corpus iuris internacional de los derechos humanos (Nogueira, 2012: 93).

En este caso, el juez nacional interpreta la norma convencional bajo la apariencia de suscribir la jurisprudencia internacional, pero, finalmente, modifica su contenido o encuentra un acomodo para concluir a la conformidad del derecho nacional con el derecho internacional de los derechos humanos (Dubois, 2007: 72). Por tanto, una de las principales consecuencias de este diálogo neutralizante es que el juez nacional hará una interpretación del derecho que no será conforme con la jurisprudencia internacional de derechos humanos ni con el nivel de protección que ella garantiza (ibid: 77).

Desde la perspectiva constitucional chilena, sería posible pensar en dos casos que podrían servir para ejemplificar esta interpretación neutralizante. Uno es el caso de la píldora del día después de 2008 y, el otro, es el requerimiento de inconstitucionalidad del proyecto de ley que moderniza el sistema de relaciones laborales de 2016. En el primer caso, los jueces constitucionales recurrieron no solo al corpus iuris interamericano de derechos humanos sino además a la interpretación de la propia Corte IDH para fundamentar su resolución en el sentido de que existía vida protegible constitucionalmente desde el momento de la concepción (STC chileno, Rol 740-2007). Recuérdese que, ante la pluralidad de informes científicos, el Tribunal Constitucional chileno resolvió en este caso que frente a una duda razonable debe prevalecer como criterio hermenéutico aquel de la norma más favorable a la persona humana ${ }^{23}$. Todo ello, en circunstancias que la Corte IDH ha sostenido que existe una

23 "Que, para dilucidar el conflicto constitucional planteado y ante la evidencia de estar estos jueces frente a una duda razonable, ha de acudirse a aquellos criterios 
persona, y por lo tanto vida susceptible de ser protegida, desde el momento de la implantación. (Corte IDH, caso Artavia Murillo y otros «Fecundación in vitro" vs. Costa Rica.). Aun cuando, hay que reconocer que esta declaración se hizo con posterioridad a la sentencia chilena de 2008. En el segundo caso, los jueces constitucionales se apoyaron en el corpus iuris internacional de los derechos de los trabajadores para intentar fundamentar su decisión de que el derecho de sindicación era un derecho individual de ejercicio individual y por lo tanto, que únicamente el individuo es el titular de dicho derecho, no la organización sindical (STC chileno, Rol 3016-2016).

e) Diálogo bajo el modo de interpretación contradictoria: diálogo oposición

El diálogo contradictorio u oposición implica una contradicción con el juez internacional -interamericano en nuestro caso-, fuente de conflictos, pero creadora de diálogos. En el diálogo oposición, hay una abierta diferencia de interpretaciones. En el diálogo neutralizante hay aparente sumisión al juez internacional, pero en definitiva bajo esa apariencia de sumisión el juez nacional interpreta la norma para preservar el derecho nacional contrario al derecho internacional —interamericano de los derechos humanos- (Dubois, 2007: 72-96).

De acuerdo con Nogueira, la interpretación que él denomina «francamente discordante», consiste en que

la jurisdicción interna del Estado considera que la resolución de la CIDH constituye una interpretación que considera incorrecta ya que no evaluó correctamente la norma de derecho interno u olvidó ponderar adecuadamente otro derecho o un atributo determinado de otro derecho que debe considerarse. El tribunal nacional en un nuevo caso sobre la misma materia, expresa su desacuerdo con la $\mathrm{CIDH}$ razonadamente, explicando los motivos del desacuerdo en el respectivo fallo, concretando un diálogo ascendente con la CIDH (Nogueira, 2012: 97).

hermenéuticos desarrollados por la teoría de los derechos fundamentales, por ser ésa la materia comprometida en el presente requerimiento.

En tal sentido, parece ineludible tener presente el principio "pro homine" o "favor libertatis" definido en la jurisprudencia de la Corte Interamericana de Derechos $\mathrm{Hu}$ manos de la siguiente forma: "Entre diversas opciones se ha de escoger la que restringe en menor escala el derecho protegido (...) debe prevalecer la norma más favorable a la persona humana" (Opinión Consultiva 5, 1985)». (Tribunal Constitucional chileno, Rol 740-2007, consid. 66..$^{\circ}$ Corte IDH, Opinión Consultiva OC-5/85, serie A 5, par. 52). 
Existen ciertas consideraciones que tienden a disuadir de la oposición abierta. Iniciando un diálogo con la Corte IDH, el juez nacional sabe que tiene más posibilidades de inyectar sus valores nacionales en la toma de decisiones de la Corte de San José que si sigue la vía alternativa, más costosa, de la defección y el conflicto abierto ${ }^{24}$.

A continuación examinaremos si los casos Eichin y Antilef y, por cierto, también Jorquera, sobre jurisdicción militar en Chile, pueden ser considerados una manifestación del rol preponderante que adquiere el juez en relación con los derechos fundamentales, y, sobre todo, una expresión de la instauración de un diálogo fecundo multinivel entre jueces en derechos humanos, en alguna de las vías interpretativas que acabamos de reseñar brevemente.

\section{LA JURISPRUDENCIA CONSTITUCIONAL SOBRE JURISDICCIÓN MILITAR}

En los casos Eichin y Antilef, ante el Tribunal Constitucional chileno, los jueces constitucionales utilizan el derecho internacional de los derechos humanos y la jurisprudencia interamericana como apoyo y sustento para adoptar el voto de mayoría. Los casos Eichin y Antilef implican un revirement de jurisprudence en relación a las decisiones anteriores del Tribunal Constitucional en esta materia. El caso Eichin trata de un requerimiento de inaplicabilidad que incide en un proceso penal por lesiones graves donde carabineros habrían efectuado el disparo de un balín durante el desarrollo de una manifestación pacífica por la educación, y dicho balín habría impactado y provocado la pérdida del ojo derecho del señor Enrique Eichin Zambrano (STC chileno, Rol 2493-13, 2014) ${ }^{25}$. En el denominado caso Eichin, Rol 2493-13, sentencia de fecha 6 de mayo de 2014, el Tribunal Constitucional objeta como inconstitucional, en el cas d'espèce, la competencia militar. Esta es una jurisprudencia constitucional sobre jurisdicción militar cuando la víctima es un civil. La sentencia de mayoría del caso Eichin reitera la doctrina y criterios expuestos por los ministros Hernán Vodanovic, Francisco Fernández, Carlos Carmona, Gonzalo García, y Juan José Romero en el caso de Francisca Jorquera Correa, Rol 2363-2012, sentencia de fecha 14 de enero de 2014 (STC chileno, ibid, consid. 3. ${ }^{\circ}$; STC chileno, Rol 2363-2012).

24 Véase, mutatis mutandis (Stone 2014: 22-26).

25 Las disposiciones legales respecto de las cuales se efectúa un reproche de constitucionalidad son los arts. 5.1 y 5.3 del Código de Justicia Militar, por ser contrarios al art. $1^{\circ}, 4^{\circ}$ y $5^{\circ}$ inciso $2^{\circ}$ y 19 , numerales $1,2,3$, de la Constitución Política. 
Cabe precisar que el caso Jorquera, anterior al caso Eichin, versa sobre un proceso penal común que se había incoado a raíz del trato físicamente vejatorio y denigrante que había recibido la estudiante Francisca Jorquera Correa por parte de Carabineros de Chile, luego de ser detenida durante el desarrollo de una jornada de movilización, el día 23 de agosto de 2012. La gestión pendiente en cuyo contexto se dedujo la acción de inaplicabilidad fue un recurso de apelación por una declinatoria de competencia en la que un tribunal de garantía se declaró incompetente a favor de la justicia militar por el delito de apremios ilegítimos y tormentos.

Por su parte, el caso Antilef trata del señor Marcos Antilef, carabinero que fue objeto de tratos vejatorios, lesiones y apremios ilegítimos — que se califican como torturas - por otros carabineros en las dependencias del retén de carabineros de Palmilla. El juez de garantía se declaró incompetente y envió el caso a la justicia militar (STC chileno, Rol 2492-13: 2). El requerimiento de inaplicabilidad solicita que se declare la inconstitucionalidad del art. 5.3 del Código de Justicia Militar que otorga a la justicia militar competencia sobre delitos comunes, por vulneración del art. 5 inciso $2 .^{\circ}, 19.3$ inciso $6 .^{\circ} \mathrm{y}$ 83 de la Constitución. Esta es una jurisprudencia constitucional que se refiere a un carabinero como víctima.

A continuación, analizaremos, por un lado, las enseñanzas constitucionales sobre los derechos reconocidos en los instrumentos internacionales de derechos humanos, particularmente, aquellos del sistema interamericano, $\mathrm{y}$, por otro, sobre la jurisprudencia emanada de la Corte IDH.

Cabe destacar que las elaboraciones constitucionales chilenas en el cas d'espece relativas a los instrumentos y a las interpretaciones provenientes de órganos jurisdiccionales internacionales, posicionan al juez constitucional como un juez común de derechos humanos, interactuando con la fuente internacional, al mismo tiempo que realiza un control de convencionalidad, como se ha descrito en la primera parte de este trabajo.

\section{LOS DERECHOS RECONOCIDOS EN INSTRUMENTOS INTERNACIONALES DE DERECHOS HUMANOS}

En esta parte se pretende abordar la pregunta de cuál es el rol y función de los derechos humanos reconocidos en instrumentos internacionales según la jurisprudencia del Tribunal Constitucional chileno. En primer lugar, se analizarán los tratados internacionales de derechos humanos como norma fundamental del bloque constitucional de derechos. En segundo lugar, examinaremos los derechos contenidos en estos instrumentos como elementos interpretativos determinantes $y$, en tercer lugar, abordaremos 
el papel significativo que juegan los estándares derivados de instrumentos internacionales de derechos humanos.

\subsection{Norma fundante del bloque constitucional de derechos fundamentales}

Los jueces constitucionales afirman que el contenido de los derechos reconocidos en los instrumentos internacionales se puede aplicar directamente como norma fundante del bloque constitucional de derechos fundamentales (Nash, 2012: 43; Nogueira, 2012: 244-252; 2008: 325-370; Fernández, 2010: 440; Tortora, 2012: 113; Machado, 2013: 124-135) ${ }^{26}$. De este modo, aun cuando la Constitución chilena no reconozca, en su texto, un determinado derecho, ello no puede constituir un obstáculo para que el juez constitucional le brinde adecuada protección. Esto se produciría por la vía del art. 5 inciso $2 .^{\circ}$ de la Constitución, que abre la misma a los tratados internacionales ratificados y vigentes en Chile. En el caso Eichin, los jueces constitucionales chilenos especifican que en el requerimiento se encuentra involucrado el respeto del mandato constitucional contenido en el art. 5 inciso $2 .^{\circ}$ de la Constitución Política (STC chileno, Rol 2493-13, consid. 6. ${ }^{\circ}$ ).

Tal como se puede apreciar en estas enseñanzas del Tribunal, los jueces constitucionales admiten expresamente que los tratados internacionales de derechos humanos, por mandato del art. 5 inciso $2 .^{\circ}$ de la Constitución pueden completar el catálogo constitucional de derechos (STC chileno, Rol 1340-2009, consid. 9..$^{\circ}$ y $10 .^{\circ}$ ). La afirmación de principio que efectúa el Tribunal Constitucional constituye una reiteración de su jurisprudencia constante en relación con la protección que el juez constitucional puede desplegar respecto de derechos que se encuentran amparados en tratados internacionales de derechos humanos. Por ejemplo, en una sentencia del 13 de mayo de 2008, los jueces constitucionales reconocieron en el orden constitucional chileno y proporcionaron amparo al derecho a la identidad personal, que no se encuentra expresamente consagrado en el texto constitucional (STC chileno, Rol 834-07, consid. 22. $\left.{ }^{\circ}\right)^{27}$.

26 En un sentido crítico, véase (Aldunate: 2008).

27 «Sobre el particular, ha de tenerse presente que aun cuando la Constitución chilena no lo reconozca expresamente en su texto [el derecho a la identidad personal], ello no puede constituir un obstáculo para que el juez constitucional le brinde adecuada protección. Lo anterior, precisamente, por su estrecha vinculación con la dignidad humana y porque tampoco puede desconocerse que él sí se encuentra protegido expresamente en diversos tratados internacionales ratificados por Chile y vigentes en nuestro país, como la Convención sobre los Derechos del Niño (artículo 7o), el Pacto 
Además, el art. 5 inciso 2. ${ }^{\circ}$ de la Constitución Política se transforma en la puerta de entrada de todo el corpus iuris interamericano e internacional de los derechos humanos al ordenamiento jurídico nacional ${ }^{28}$. El art. 5 de la Constitución, es, por tanto, el requisito formal para que el procedimiento de inaplicabilidad prospere al encontrar una disconformidad entre una norma legal y una norma de un tratado internacional. Si esto ocurre, se produce la vulneración del art. 5 inciso 2.0 de la Constitución ${ }^{29}$.

\subsection{Elemento interpretativo determinante o papel significativo de los estándares internacionales}

El contenido de los derechos reconocidos en los tratados internacionales de derechos humanos puede ser asumido como elemento interpretativo determinante para extraer todos los posibles significados de los derechos según los contextos en que aparece. Los jueces constitucionales afirman en el caso Eichin que los derechos reconocidos en los tratados internacionales de derechos humanos pueden aplicarse directamente, como parte del bloque constitucional de derechos o indirectamente como elemento interpretativo determinante para la plenitud de los derechos que reconoce la Constitución Política. Así, el Tribunal Constitucional ha señalado:

Que, entonces, la significación de tales derechos en los referidos instrumentos no puede desatenderse en el presente juzgamiento, sea que se estime su aplicación directa como norma fundante del bloque constitucional de derechos, sea que se entienda su contenido como una referencia o elemento interpretativo determinante en la plena acepción de los derechos involucrados que reconoce la Constitución Política (STC chileno, Rol 2493-13, consid. 7. ${ }^{\circ}$ ).

Internacional de Derechos Civiles y Políticos (artículo 24.2) y la Convención Americana de Derechos Humanos (artículo 18)».

28 «Ese cuerpo jurídico interamericano está formado por las sentencias que son obligatorias para las partes, y fuera de ellas las sentencias, las opiniones consultivas (OC) y las resoluciones de la Comisión IDH, que al final de cuentas también son ejercicios de interpretación de la Convención Americana y juntas son guías de interpretación para otros casos incluyendo en el foro interno" (Becerra 2013: 121).

29 En el caso Antilef el Tribunal ha señalado: «[L]a vulneración de los derechos a ser oído por un juez o tribunal competente, a un proceso público y a ser juzgado por un tribunal independiente e imparcial, constituye un conjunto de infracciones al artículo $8^{\circ}$ de la Convención Americana de Derechos Humanos. Este artículo tiene su correspondencia en el orden constitucional chileno a través del artículo $5^{\circ}$, inciso segundo, de la Constitución» (Tribunal Constitucional chileno, Rol 2492-13, consid. 23. ${ }^{\circ}$ ). 
Además, en Eichin, el Tribunal Constitucional efectúa una lectura conjunta, complementaria y que completa la Convención Americana sobre Derechos Humanos y la Constitución Política de Chile, particularmente, entre el art. 8 de la Convención Americana sobre Derechos Humanos (en adelante $\mathrm{CADH}$ ) y el art. 19.3 de la Constitución. Desde esta perspectiva, se puede sostener que el Tribunal Constitucional adopta, positivamente, un enfoque de derechos siguiendo el principio de la protección integral ${ }^{30}$. El principio de la protección integral posee múltiples funciones, pero una de ellas consiste en esta interpretación integrada y optimizadora de los derechos fundamentales $^{31}$. Con todo, debe precisarse, que la estructura mínima para esta lectura conjunta es considerar los arts. 8 y 25 de la CADH y 19.3 de la Constitución (Aguilar, 2010: 709-744). De este modo, los jueces constitucionales han reafirmado la doble articulación entre derecho internacional de los derechos humanos y derecho constitucional ${ }^{32}$.

Asimismo, los estándares que se derivan de los tratados internacionales de derechos humanos juegan un papel significativo en el análisis de constitucionalidad en casos de violación de derechos fundamentales, de acuerdo con la

30 Meléndez ha señalado que «si en el proceso de interpretación judicial de las normas de derechos humanos se toman en consideración lo que sobre cada materia regula tanto el derecho interno como el derecho internacional, y se aplica — con una visión coherentemente racional — la disposición más favorable al individuo, no solo se estaría haciendo una interpretación integral del sistema jurídico vigente, sino además, se estaría actuando como un juez justo y racional, como un juez de la Constitución, respetuoso de los derechos humanos y las libertades fundamentales» (Meléndez, 2012: 132).

31 Sobre este tipo de interpretación en la jurisprudencia constitucional comparada véase (STC peruano, $\mathrm{N}^{\circ}$ 2730-2006-PA/TC., para. 15; Nº1412-2007-PA/TC. para. 18); «Estos valores (la libertad, la justicia, la igualdad y el pluralismo político) traen consigo una axiología nuclear en la interpretación de todo derecho fundamental, la combinación axiológica respectiva da como resultado un tipo de Estado, que en nuestro caso se resuelve en una fórmula integrativa» (Garrido 2011: 23-52).

32 «[A] la luz de tales antecedentes, no cabe duda que la aplicación conjunta de los preceptos impugnados provoca una vulneración de los derechos a ser oído por un juez competente, a la publicidad del proceso y a ser juzgado por un tribunal independiente e imparcial, con transgresión de los preceptos contenidos en el artículo 8 de la Convención Americana sobre Derechos Humanos y en el artículo 19, $\mathrm{N}^{\circ} 3^{\circ}$, de la Constitución Política de la República» (Tribunal Constitucional Chileno, Rol 24932013, consid. $9 .^{\circ}$ ). 
posición asumida en Antilef ${ }^{33}$. En efecto, el Tribunal Constitucional destaca, en el caso Antilef, que los estándares contenidos en los instrumentos internacionales tendrán «un papel significativo» en su jurisprudencia ${ }^{34}$.

En este sentido, ¿cuáles serían los nuevos estándares en materia de justicia militar? Los nuevos estándares en materia de justicia militar a partir del orden internacional de los derechos humanos se podrían especificar, por ejemplo, en el Pacto Internacional de Derechos Civiles y Políticos ${ }^{35}$.

Hasta ahora hemos visto el valor asignado a los instrumentos internacionales de derechos humanos, y corresponde pasar a examinar el valor que juega la jurisprudencia internacional en la reflexión de los jueces constitucionales.

\section{LA JURISPRUDENCIA DE LA CORTE INTERAMERICANA DE DERECHOS HUMANOS}

El Tribunal Constitucional, en el caso Eichin, asume expresamente una parte muy relevante del contenido operativo del control de convencionalidad, consistente en admitir que la Corte IDH es el intérprete auténtico de la $\mathrm{CADH}^{36}$. En efecto, en este caso, los jueces constitucionales reconocen expresamente los contenidos básicos de la doctrina del control de convencionalidad y,

33 Los estándares internacionales de derechos humanos se pueden entender como «el conjunto de instrumentos internacionales de derechos humanos, negociados o aceptados, ya sean vinculantes o no. En consecuencia, los estándares incluyen documentos vinculantes que codifican o crean obligaciones o deberes jurídicos, lo que se conoce comúnmente como hard law, así como los documentos no vinculantes que formulan recomendaciones sobre normas de conducta y políticas públicas que debieran adoptar los Estados, conocidos como soft law» (International Council on Human Rights, 2006:4).

«[E]n el examen para acoger este requerimiento tendrá un papel significativo el establecimiento de nuevos estándares en materia de justicia militar a partir de la obligación impuesta al Estado de Chile, incluyendo a esta jurisdicción constitucional, en orden al deber de respetar y promover los derechos garantizados por esta Constitución y por los tratados internacionales, ratificados y vigentes en Chile» (Tribunal Constitucional Chileno, Rol 2492-13, consid. $\left.17 .^{\circ}\right)$.

35 «Que partiremos del análisis del artículo 14 del Pacto Internacional de Derechos Civiles y Políticos, que establece un conjunto de garantías sustantivas y procedimentales del debido proceso, especialmente, el penal» (STC, Ibid, consid.18).

36 "Que la Corte Interamericana de Derechos Humanos, intérprete auténtico de la aludida convención, ha sentado jurisprudencia en orden a que la justicia militar carece de jurisdicción sobre intervinientes civiles y que sólo puede investigar y sancionar la afectación de bienes jurídicos relacionados con la función castrense» (Tribunal Constitucional chileno, Rol 2493-2013, consid. 8). 
en íntima vinculación, conforman las obligaciones internacionales del Estado. Una de estos deberes consiste en la obligación de adecuar el ordenamiento jurídico interno a los estándares internacionales, cuyas fuentes principales son los principios generales del derecho, el derecho consuetudinario, y el derecho convencional internacional (STC chileno, Rol 2493-2013, consid. 12. ${ }^{\circ}$ ). En este caso, en particular, el Tribunal Constitucional se estaría refiriendo a las disposiciones de la sentencia Palamara Iribarne vs. Chile de la Corte Interamericana.

Los criterios fijados por la jurisprudencia de la Corte IDH pueden ser considerados, según la jurisprudencia del Tribunal Constitucional, como elementos significativos para el razonamiento jurisprudencial y como elementos complementarios de análisis en la práctica judicial constitucional. La distinción entre uno y otro va a variar según si el Estado ha sido parte o no en el caso interamericano de cuya jurisprudencia se trata.

De esta manera, por un lado, según el Tribunal Constitucional chileno, los estándares internacionales de protección de los derechos humanos desarrollados por la jurisprudencia derivada de casos en los que el Estado de Chile es parte se consideran como elementos significativos para el razonamiento jurisdiccional. En efecto, en el caso Eichin — que reenvía al caso Jorquera-, los jueces constitucionales se refirieron a la normativa interamericana de derechos humanos y a la jurisprudencia de la Corte IDH, particularmente a aquella que emana de procesos seguidos contra Chile, como el asunto Palamara Iribarne vs. Chile. En este caso, los ministros mencionados destacan los estándares emanados de esta sentencia como «significativos» para resolver el requerimiento ${ }^{37}$. Este relevante criterio ha sido reiterado en el caso Antilef (STC chileno, Rol 2492-13, consid. 19. ${ }^{\circ}$.

Mientras que, por otro lado, de acuerdo con los jueces constitucionales chilenos, los estándares internacionales de protección de los derechos humanos desarrollados por la jurisprudencia y derivados de casos en los que el Estado de Chile no ha sido parte se consideran como un elemento complementario de análisis. Así, en el caso Eichin — que reenvía al caso Jorquera-, los ministros del voto por acoger se apoyan en la jurisprudencia de la Corte IDH, pero esta

37 "Que, más significativo para este asunto, es la jurisprudencia de la Corte Interamericana de Derechos Humanos, a partir de la Sentencia de la Corte IDH: Palamara Iribarne vs. Chile, Serie $\mathrm{C} \mathrm{N}^{\circ} 135$, a partir de este fallo CIDH/N $\left.{ }^{\circ} 135 / 2005\right)$. No es posible hacer una revisión de una extensa sentencia; sin embargo, condensaremos algunos estándares a partir del reconocimiento de que Chile ha violado determinados derechos de la Convención Americana de Derechos Humanos» (Tribunal Constitucional chileno, Rol 2363-2012, consid. 16. ${ }^{\circ}$ ). 
vez, una jurisprudencia emanada de casos donde Chile no ha sido parte. En este caso, los ministros del voto por acoger, refieren a dichos estándares como «un elemento complementario de análisis» ${ }^{38}$.

Ya sea como elemento significativo para el razonamiento jurisprudencial constitucional, o bien, como elemento complementario de análisis, el uso que hacen los jueces constitucionales chilenos de las enseñanzas interamericanas, primero, reflejan un diálogo entre jueces, y, segundo, este diálogo adquiere, en nuestra opinión, la modalidad de una interpretación conforme y constructiva, en el sentido de que mejora el estándar nacional vigente.

Cabe resaltar que no se trata de la primera vez que el Tribunal Constitucional recurre al uso de la jurisprudencia interamericana. En las sentencias de mayoría se ha usado la Opinión Consultiva Colegiación Obligatoria de Periodistas de 1985. (Corte IDH, Opinión Consultiva OC-5/85, serie A 5, par. 55; STC chileno, Rol 2358-12). En votos separados se ha usado, por ejemplo, el caso Herrera Ulloa vs. Costa Rica; Ricardo Canese vs. Paraguay y Tristán Donoso vs. Panamá, casos donde el Estado de Chile no ha sido parte (STC chileno, Rol 1798-10).

\section{CONCLUSIONES}

Los casos Eichin y Antilef del Tribunal Constitucional chileno - y también el caso Jorquera - sirven para ilustrar la evolución que ha experimentado la aplicación del derecho internacional de los derechos humanos por la magistratura constitucional en los últimos tiempos, y a partir de estos ejemplos, se puede analizar si ellos son representativos de un cambio de paradigma jurídico en el derecho, de la emergencia de un nuevo derecho público y del desarrollo práctico de un diálogo entre jueces. Una investigación mayor de la jurisprudencia constitucional chilena afuera de la temática de la jurisdicción militar es necesaria para poder seguir construyendo este argumento.

¿Podrían estos casos ser considerados una muestra del rol protagónico del juez bajo el prisma de un nuevo paradigma jurídico? Cuando el Tribunal

38 «Que, por último, en materia de estándares, cabe agregar como un elemento complementario de análisis el criterio que ha tenido la propia Corte Interamericana de Derechos Humanos en el Caso Radilla Pacheco vs. México en sentencia del 23 de noviembre de 2009, excepcionando de la jurisdicción militar los actos delictivos cometidos por militares respecto de bienes jurídicos no militares. Siendo sus víctimas civiles, bajo ninguna circunstancia los juzgaría la justicia militar» (Tribunal Constitucional chileno, ibid, consid. $19 .^{\circ}$ ). 
Constitucional —en los casos Eichin y Antilef - aplica los instrumentos internacionales de derechos humanos, pero, sobre todo, la jurisprudencia interamericana, da cuenta, de este cambio de paradigma, el cual se materializa por la vía de un diálogo conforme.

¿Podrían estos casos constituir un ejemplo del rol protagónico del juez en el contexto de un nuevo derecho público? Eichin y Antilef constituyen, a nuestro modo de ver, ejemplos paradigmáticos de este nuevo derecho público cuya creación no releva ya de la autoridad exclusiva del Estado. En este sentido, el juez nacional juega un papel destacado. Por eso, el rol protagónico del juez es que uno de los rasgos distintivos de este cambio de paradigma y nuevo derecho público. Eichin y Antilef lo han dejado meridianamente claro. Los jueces constitucionales instauran un diálogo entre jueces multinivel, que apunta a adecuar el Código de Justicia Militar y la práctica judicial existente respecto de la competencia de los tribunales militares, a los estándares más favorables desarrollados pretorianamente por el juez interamericano. Para estos efectos, el Tribunal Constitucional recurre a los instrumentos internacionales convencionales, pero, sobre todo, utiliza, en forma creciente, métodos interpretativos modernos e idóneos en el campo de los derechos humanos, demostrativos de un diálogo creciente de carácter multinivel.

¿Existe en estos casos un diálogo entre jueces? Asimismo, Eichin y Antilef demuestran una tímida, pero promisoria, preocupación de los jueces constitucionales por establecer un diálogo con los jueces interamericanos. De lo anterior, da cuenta no solo la referencia a jurisprudencia relativa a Chile, tal como el caso Palamara Iribarne, sino también el uso de jurisprudencia referida a otros Estados partes en la Convención Americana sobre Derechos Humanos, tal como el caso Radilla Pacheco vs. México. En Eichin y Antilef, los jueces constitucionales adecuaron el Código de Justicia Militar y, por sobre todo, la interpretación que hasta el momento provenía de la práctica judicial, a los estándares establecidos por la Convención Americana sobre Derechos Humanos y por la interpretación de la Corte IDH. Por esta razón, como se ha sostenido a lo largo de este estudio, se podría sostener que el Tribunal Constitucional chileno, en Eichin y Antilef, instauró un diálogo con los jueces interamericanos bajo la modalidad de la interpretación conforme. Aun cuando no ha sido desarrollado en este artículo, con posterioridad a estas sentencias, la Corte Suprema se ha unido en forma sistemática al criterio fijado por el Tribunal Constitucional, estableciendo en forma horizontal un fructífico diálogo conforme. Resta por ver, si en el futuro el Tribunal Constitucional persistirá en esta voluntad de establecer un diálogo multinivel entre jueces que apunte no a la sumisión sino más bien la prevalencia de la solución más favorable para el individuo. 


\section{Bibliografía}

Aguilar Cavallo, G. (2010). Hacia un mayor acceso a la justicia en el proceso penal. Estudios Constitucionales, 8 (2), 709 - 744. Disponible en: https://doi.org/10.4067/ S0718-52002010000200021.

_ (2013). Diálogo judicial multinivel. En H. Nogueira Alcalá (coord.). Diálogo judicial multinivel y principios interpretativos favor persona $y$ de proporcionalidad (pp. 55-102). Santiago de Chile: Librotecnia.

— y Nogueira Alcalá, H. (2016). El principio favor persona en el derecho internacional y en el derecho interno como regla de interpretación y de preferencia normativa. Revista de Derecho Público, 8, 13-43. Disponible en: https://doi.org/10.5354/07195249.2016.43057.

Aldunate Lizana, E. (2008). Derechos fundamentales. Santiago de Chile: Legal Publishing. Allard, J. (2008). Le dialogue des juges à la Cour européenne des droit de l'homme et à la Cour suprême des Etats-Unis. Constats et perspectives philosophiques. En J. Allard et al. Juger les droits de l'homme: l'Europe et les Etats-Unis face à face (pp. 93-138). Bruxelles: Bruylant.

Andriantsimbazovina, J. (2005). La prise en compte de la Convention européenne des droits de l'homme par le Conseil constitutionnel, continuité ou évolution? Cahiers $d u$ Conseil Constitutionnel, 18, 148-153.

Becerra Ramírez, M. (2013). El control de la aplicación del derecho internacional en el marco del Estado de derecho. México: Instituto de Investigaciones Jurídicas-UNAM.

Bogdandy, A. V. (2013). Ius constitutionale commune latinoamericanum. Una aclaración conceptual desde una perspectiva europea. En L. González Pérez y D. Valadés (coords.). El constitucionalismo contemporáneo. Homenaje a Jorge Carpizo (pp. 39-66). México: Instituto de Investigaciones jurídicas, UNAM.

Cartabia, M. (2009). L'universalitá dei diritti umani nell'etá dei 'nuovi diritti, Quaderni Costituzionali, 29 (3), 537-568.

— (2017). I «nuovi» diritti. Centro studi sugli Enti ecclesiastici. Disponible en: http:// www.olir.it/areetematiche/166/documents/cartabia_relazione_2010_roma_cesen. pdf.

Cassetti, L. (2010). Il diritto di 'vivere con dignità' nella giurisprudenza della Corte Interamericana dei diritti umani. Rivista di diritto pubblico italiano, comunitario e comparato, 23, 1-17.

Dubois, J. (2007). La neutralisation. Dialogue des juges et interprétation neutralisante. Cahiers de l'IDEDH, consacrées au thème du "dialogue des juges», 11, 72-96.

Dubout, E. y Touze, S. (2009). La fonction des droits fondamentaux dans les rapports entre ordres et systèmes juridiques. En E. Dubout y S. Touze (dir.). Les droits fondamentaux: charnières entre ordres et systèmes juridiques (pp. 11-35). Paris: Pedone.

Dulitzky, A. E. (2015). An Inter-American Constitutional Court? The Invention of the Conventionality Control by the Inter-American Court of Human Rights. Texas International Law Journal, 50 (1), 45-93. 
Fernández González, M. A. (2010). La aplicación por los tribunales chilenos del derecho internacional de los derechos humanos. Estudios Constitucionales, 8 (1), 425-442. Disponible en: https://doi.org/10.4067/S0718-52002010000100016.

Ferrer Mac-Gregor, E. (2011). Interpretación conforme y control difuso de convencionalidad. El nuevo paradigma para el juez mexicano. Estudios Constitucionales, 9 (2), 531-622.

Frosini, V. (1991). L'interpretazione dei diritti umani. Rivista Pace, diritti dell'uomo, diritti dei popoli, V (1), 9-19.

García Roca, J. (2010). El margen de apreciación nacional en la interpretación del Convenio Europeo de Derechos Humanos: soberania e integración. Madrid: Civitas-Thomson Reuters.

Garrido Gómez, M. (2001). Aspectos e implicaciones de una interpretación integral-material de los derechos fundamentales. Derechos y Libertades: Revista del Instituto Bartolomé de las Casas, VI (10), 23-52.

Giorgianni, M. (2014). Il rapporto fra la Convenzione europea dei diritti dell'uomo e la Carta dei diritti fondamentali dell'Unione Europea nel dialogo fra le Corti europee e nazionali: il problema dell'interpretazione dei diritti umani. Diritti Comparati. Disponible en: http://www.diritticomparati.it/2014/07/il-rapporto-fra-la-convenzione-europea-dei-diritti-delluomo-e-la-carta-dei-diritti-fondamentali-dell.html.

Gouttes, Régis de (1999). La Convention européenne des droits de l'homme et le juge français. Revue internationale de droit comparé, 51 (1), 7-20. Disponible en : https:// doi.org/10.3406/ridc.1999.18315.

Grabarczyk, K. (2007). Dialogue des juges : éléments d'analyse. Propos introductifs. Cahiers de l'IDEDH consacrées au thème du «dialogue des juges», 11, 10-41.

Häberle, P. (2010). Métodos y principios de interpretación constitucional. Un catálogo de problemas. Revista de Derecho Constitucional Europeo, 7, 379-411.

Habermas, J. (2010). La idea de dignidad humana y la utopía realista de los derechos humanos. Anales de la Cátedra Francisco Suárez, 44, 105-121.

Hennebel, L. (2007). Les références croisées entre les juridictions internationales des droits des l'homme. En Le dialogue des juges. Actes du colloque organisé le 28 avril 2006 à l'Université libre de Bruxelles (pp. 31-76). Les Cahiers de l'Institut d'études sur la Justice. Bruxelles: Bruylant.

Hertig Randall, M. (2012). Le dialogue entre le juge suisse et le juge européen. En F. Bellanger; et J. Werra. Genève au confluent du droit interne et du droit international : Mélanges offerts par la Faculté de droit de l'Université de Genève à la Société suisse des juristes à l'occasion du congrès 2012 (pp.19-59). Zürich: Schulthess.

International Council on Human Rights. (2006). Human Rights Standards: Learning from Experience. International Council on Human Rights Policy. Switzerland: Versoix.

Jacquelot, F. (2006). Le juge constitutionnel et le droit comparé. Les Petite Afiches, Journaux judiciaires associés, $12,8$.

Lavade, A. (2005). Constitution et Europe ou le juge constitutionnel au cœur des rapports de systèmes. Cahiers du Conseil Constitutionnel, 18, 133-137. 
Le Pourhiet, A. (2010). L'allégeance des juges nationaux au juge européen. Constitutions. Revue de droit constitutionnel appliqué, 3, 363-365.

Levinet, M. (2011). La Convention européenne des droits de l'homme socle de la protection des droits de l'homme dans le droit constitutionnel européen. Revue française de droit constitutionnel, 86, 227-263. Disponible en : https://doi.org/10.3917/ rfdc.086.0227.

Machado Cyrillo da Silva, C. (2013). La posición jerárquica del derecho internacional de los derechos humanos en las Constituciones sudamericanas. Revista Contextos, 5, 124-135.

Madelaine, C. (2007). L'anticipation. Manifestation d'un dialogue «vrai» entre juge national et juge européen? Cahiers de l'IDEDH, consacrées au thème du «dialogue des juges», 11, 129-156.

Martens, P. (2007). L'ébauche d'une culture commune des cours suprêmes ou constitutionnelles. En Le dialogue des juges. Actes du colloque organisé le 28 avril 2006 à l'Université libre de Bruxelles (pp. 9-30). Les Cahiers de l'Institut d'études sur la Justice. Bruxelles: Bruylant.

Maus, D. (2004). La Charte des Droits Fondamentaux de l'Union Européenne et la Protection des Droits de l'Homme en Europe. Disponible en: http://www.us-rs.si/media/ zbornik.pdf.

Meléndez, F. (2012). Instrumentos internacionales sobre derechos humanos aplicables a la administración de justicia. Estudio constitucional comparado. Bogotá: Editorial de la Universidad del Rosario-KAS.

Milano, L. (2006). Les lois rétroactives, illustration de l'effectivité du dialogue des juges. Revue Française de Droit Administratif, 3, 447-462.

Motolese, L. (2013). La Corte Europea dei Diritti dell'Uomo: Tecniche di decisione e criteri di interpretazione conforme alla Convenzione Europea. Disponible en: http://www. contabilita-pubblica.it/2013/Dottrina/Motolese.pdf.

Nash Rojas, C. (2012). Derecho internacional de los derechos humanos en Chile: recepción y aplicación en el ámbito interno. Santiago de Chile: Centro de Derechos Humanos.

Nogueira Alcalá, H. (2006). Lineamientos de interpretación constitucional y del bloque constitucional de derechos. Santiago de Chile: Librotecnia.

— (2008). La evolución político-constitucional de Chile 1976-2005. Estudios Constitucionales, 6 (2), 325-370. Disponible en: https://doi.org/10.4067/S071852002008000100011.

— (2014). Derechos fundamentales, bloque constitucional de derechos, diálogo interjurisdiccional y control de convencionalidad. México: Ubijus.

Pelloux, R. (1981). Les arrêts rendus par la Cour européenne des Droits de l'homme en 1980. Annuaire français de droit international, 27, 286-303. Disponible en : https:// doi.org/10.3406/afdi.1981.2445.

Ponthoreau, M. (2005). Le droit comparé en question(s) entre pragmatisme et outil épistémologique. Revue International de Droit Comparé, 1, 7-27. Disponible en : https://doi.org/10.3406/ridc.2005.19331. 
Riochet, D. (2007). La conformité. L'interprétation conforme à la Convention européenne des droits de l'homme. Cahiers de l'IDEDH, consacrées au thème du «dialogue des juges», 11, 97-128.

Rolland, P. (1990). Le contrôle de l'opportunité par la Cour européenne des droits de l'homme, Conseil Constitutionnel et Cour européenne des droits de l'homme, Droits et Libertés en Europe. Actes du colloque de Montpellier, 20-21, 70-74.

Saiz Arnaiz, A. (2015). La interpretación de conformidad: significado y dimensión práctica (un análisis desde la Constitución española). En L. López Guerra, y A. Saiz Arnaiz. Los sistemas interamericano y europeo de protección de los derechos humanos (pp. 279-326). Lima: Palestra.

Sudre, F. (2001). A propos du dynamisme interprétatif de la Cour Européenne des droits de l'homme. La Semaine Juridique, 28 (1), 335-437.

- (2003). Droit européen et international des droits de l'homme. Paris: PUF.

(2004). À propos du dialogue des juges et du contrôle de conventionalité. En Etudes en l'honneur de Jean-Claude Gautron. Les dynamiques du droit européen en début du siècle. Paris: Pedone.

— (2007). Avant-propos. Cahiers de l'IDEDH, consacrées au thème du «dialogue des juges», 11, 7-9.

Suxe, H. (2007). La dimension objective du dialogue des juges. Cahiers de l'IDEDH, consacrées au thème du «dialogue des juges», 11, 158-191.

Tizzano, A. (2011). Les Cours européennes et l'adhésion de l'Union à la CEDH. Rivista Il Diritto dell'Unione Europea, 1, 29-57.

Tortora Aravena, H. (2012). Bases constitucionales de la libertad de conciencia y culto en Chile. Revista de Derechos Fundamentales, 7, 87-115.

Tria, L. (2014). La tutela dei diritti fondamentali. Le tecniche di interrelazione normativa indicate dalla Corte costituzionale. L'abilità di usare il patrimonio di sapienza giuridica ereditato dal passato per preparare il futuro, 34. Disponible en: http://www. cortecostituzionale.it/documenti/convegni_seminari/STU_274.pdf.

Tulkens, F. y Van Drooghenbroeck, S. (2005). Le droit au logement dans la Convention Européenne des Droits de l'homme. Bilan et Perspectives. En N. Bernard y C. Mertens (dirs.). Le logement dans sa multidimensionnalité. Une grande cause régionale (pp.311-325). Ministère de la Région Wallone.

Vescovi, E. (1998). La jurisdicción nacional e internacional en Latinoamérica. La defensa de los derechos humanos en la región. Integración jurisdiccional. Derecho transnacional. Derecho comunitario. Papel de los jueces. En Liber Amicorum Héctor Fix-Zamudio (pp. 1553-1567). Costa Rica: Secretaría de la Corte Interamericana de Derechos Humanos.

Wildhaber, L. (2004). La giurisprudenza evolutiva della Corte europea dei diritti umani. Pace diritti umani, 1, 15-27. 